УДК 676.164.3.023.1

\title{
ОТБЕЛКА СУЛЬФАТНОЙ ЦЕЛЛЮЛОЗЫ ПЕРОКСИДОМ ВОДОРОДА И ХЛОРИТОМ НАТРИЯ
}

\author{
() Ф.Х. Хакимова ${ }^{1 *}$, К.А. Синяев ${ }^{1}$ \\ Пермский национальный исследовательский политехнический университет, \\ ГСП, пр. Комсомольский, 29, Пермь, 614990 (Россия), e-mail: tcbp@pstu.ru
}

Разработана схема отбелки сульфатной целлюлозы пероксидом водорода и хлоритом натрия, которая упрощает технологию отбелки за счет исключения КЩО под давлением и производства на предприятии $\mathrm{ClO}_{2}$ из хлората натрия. Предлагаемая схема отбелки целлюлозы включает делигнификацию целлюлозы пероксидом водорода в кислой среде с последующей щелочной обработкой (вместо КЩО) и отбелку ее хлоритом натрия (в кислой среде) в две ступени с промежуточным окислительным щелочением, т.е. получена схема Пк - Щ - Хт ${ }_{1}-$ ЩП - Хт 2 - К. Установлены степени окислительной и гидролитической деструкции целлюлозы, закономерности изменения физико-химических, структурных и морфологических свойств волокон целлюлозы в процессе отбелки и влияние этих характеристик на показатели качества беленой целлюлозы. Все это свидетельствует о весьма избирательном делигнифицирующем и мягком отбеливающем воздействии на целлюлозу принятой схемы отбелки при оптимизированных условиях.

Ключевые слова: сульфатная целлюлоза, отбелка, пероксид водорода, хлорит натрия, свойства волокон, характеристика целлюлозы.

\section{Введение}

Основная тенденция развития отбелки целлюлозы - создание и внедрение экологически безопасных технологий. Для решения этой задачи наиболее удачной и экономически целесообразной на сегодняшний день считается переход на ЕСF-технологию. Такая технология в последние годы включает кислороднощелочную делигнификацию (КЩО) и применение в качестве отбельных реагентов диоксида хлора, пероксида водорода, озона.

При отбелке сульфатной целлюлозы наиболее эффективной делигнифицирующей стадией считается КЩО. Недостаток КЩО заключается в необходимости проведения процесса под давлением и, соответственно, конструктивно сложного оборудования.

При отбелке сульфатной хвойной целлюлозы весьма распространенной является добелка ее после КЩО диоксидом хлора в две ступени с промежуточной щелочной обработкой, т.е. схема КЩО - Д - Щ - Д. Однако такая отбелка требует наличия на целлюлозно-бумажных предприятиях производства диоксида хлора $\left(\mathrm{ClO}_{2}\right)$.

В связи с этим представляют интерес исследования по упрощению технологии отбелки при сохранении качества беленой целлюлозы.

В последние годы проводятся исследования по делигнификации целлюлозы пероксидом водорода в кислой среде. Так, автор работы [2] считает, что при отбелке лиственной сульфатной целлюлозы такая де-

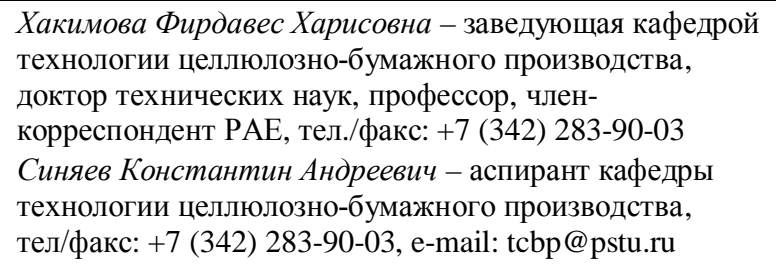
технологии целлюлозно-бумажного производства, доктор технических наук, профессор, членкорреспондент РАЕ, тел./факс: +7 (342) 283-90-03 Синяев Константин Андреевич - аспирант кафедры технологии целлюлозно-бумажного производства, тел/факс: +7 (342) 283-90-03, e-mail: tcbp@ pstu.ru лигнифицирующая обработка дает лучшие результаты, чем КЩО, при значительно меньшей деструкции целлюлозы. Условия предварительной кислотной обработки достаточно приемлемые для производства, а экологическая безопасность такой делигнификации даже несколько выше, чем КЩО.

\footnotetext{
* Автор, с которым следует вести переписку.
} 
Результаты работы А. Парен и Й. Яакара [3] показали, что пероксид водорода, активированный молибдатом натрия, - сравнительно недорогой метод делигнификации, который может быть внедрен на уже существующих отбеливающих установках без каких-либо значительных капитальных затрат. Авторами показано, что такая делигнификация сульфатной целлюлозы (число Каппа 8-12) при $80{ }^{\circ} \mathrm{C}$ в течение 180 мин приводит к удалению из целлюлозы 40-50\% лигнина. Пероксомолибдат можно использовать для отбелки как лиственной, так и хвойной целлюлозы. Делигнификация пероксидом водорода, активированным молибдатом натрия, успешно апробирована в промышленных условиях [3].

В работах $[6,7]$ также приведены результаты исследований по кислой пероксидной отбелке целлюлозы с применением пероксомолибдатных катализаторов: проведена оптимизация данной стадии отбелки эвкалиптовой крафт-целлюлозы и показана возможность ее использования путем включения в промышленную схему отбелки (КЩО - П $-\mathrm{O}_{3}-$ Д - П) [6]; авторы работы [7] пришли к заключению, что активированный молибдатами пероксид водорода можно считать избирательным отбеливающим реагентом, эффективным и для делигнификации, и для удаления из лиственной древесины гексенуроновых кислот.

Цель данного исследования состояла в упрощении технологии отбелки сульфатной хвойной целлюлозы и повышении ее экологичности следующим образом:

- проведением делигнификации целлюлозы пероксидом водорода (в кислой среде), активированным молибдатом натрия (Пк), с последующей щелочной обработкой, т.е. исключением КЩО из схемы отбелки сульфатной целлюлозы;

- отбелкой целлюлозы (после ступени делигнификации) хлоритом натрия (Хт) вместо диоксида хлора, что позволит исключить из состава предприятия специальное производство диоксида хлора.

В результате предлагаемая схема отбелки по ЕCF-технологии получила вид: Пк - Щ - $\mathrm{XT}_{1}-$ ЩП $\mathrm{X}_{2}$, для оценки возможности и целесообразности применения которой на отбелку сульфатной хвойной целлюлозы необходимо было установить закономерности изменения физико-химических, структурных и морфологических свойств волокон и целлюлозы в процессе отбелки и влияние этих характеристик на показатели качества полученной беленой целлюлозы.

\section{Материалы и методы исследования}

Для исследований использована сульфатная промышленная целлюлоза с довольно высоким числом Каппа - 33,6 (массовая доля лигнина 5,1\%). В ходе исследований применялся системный подход, охватывающий математическое моделирование, стандартные и оригинальные методики анализа, используемые в промышленном контроле и исследовательской практике по целлюлозно-бумажному производству, с применением современных измерительных средств и вычислительной техники. Так, для анализа результатов экспериментов и расчетов оптимальных режимов обработки целлюлозы использован программный пакет статистического анализа данных Statgraphics Plus Version 5.0. [4]; для определения комплекса свойств образцов целлюлозы и геометрических параметров волокон использовался анализатор L\&W FiberTester.

\section{Результаты исследования и их обсуждение}

С целью повышения эффективности отбелки по предложенной схеме выполнена оптимизация условий отбелки целлюлозы и расхода отбеливающих реагентов по ступеням Пк, $\mathrm{XT}_{1}$ и $\mathrm{X}_{2}$. Поставлены три эксперимента по плану Бокса (при $\mathrm{m}=3$ ), включающих по 14 экспериментальных точек. Результаты программной обработки полученных данных всех экспериментов с построением карт Парето и графиков диагностики отклонения ошибок прогноза значений выходных параметров от нормального распределения, полученные математические модели процессов и оптимальные условия (расчетные и экспериментальные) приведены в статье [5]. В данной работе представлены результаты исследования влияния отбелки целлюлозы при оптимальных условиях на механические и физико-химические показатели, позволяющие проследить характер измене-

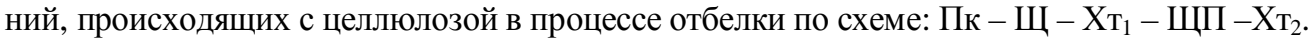

В таблице 1 приведены условия обработки целлюлозы на ступенях отбелки, а в таблице 2 - изменения основных характеристик целлюлозы в процессе отбелки.

Отбелкой при оптимальных условиях целлюлозы с высокой долей лигнина $(5,1 \%)$ получена белизна $88,0 \%$.

Для сравнения по разработанной схеме при тех же условиях проведена отбелка белимой хвойной целлюлозы производства ЗАО «Интернешнл Пейпер» (число Каппа 30). В соответствии со степенью провара был снижен расход хлорита натрия на ступени $\mathrm{X}_{2}$ до $0,8 \%$ в ед. $\mathrm{ClO}_{2}$. Белизна беленой целлюлозы составила 90,3\%. Разрывная длина целлюлозы в результате отбелки снизилась на 7,3\% (с 10300 м для небеленой целлюлозы до 9550 м - для беленой). 
Таблица 1. Условия обработки сульфатной хвойной целлюлозы на отдельных ступенях отбелки

\begin{tabular}{|c|c|c|c|}
\hline \multirow[t]{2}{*}{$\begin{array}{c}\text { Реагенты для обработки и условия } \\
\text { обработки }\end{array}$} & \multicolumn{3}{|c|}{$\begin{array}{l}\text { Оптимальные условия обработки и расход реагентов по ступеням отбелки, } \\
\text { \% от абс.сух.волокна }\end{array}$} \\
\hline & Пк & $\mathrm{XT}_{1}$ & $\mathrm{X}_{2}$ \\
\hline $\mathrm{H}_{2} \mathrm{O}_{2}$ & 4,68 & - & - \\
\hline $\mathrm{H}_{2} \mathrm{SO}_{4}$ & 1,00 & - & - \\
\hline $\mathrm{Na}_{2} \mathrm{MoO}_{4}$ & 0,10 & - & - \\
\hline $\mathrm{NaClO}_{2}\left(\right.$ ед. $\left.\mathrm{ClO}_{2}\right)$ & - & 1,83 & 0,87 \\
\hline $\mathrm{HCl}$ & - & 1,50 & 1,50 \\
\hline Температура, ${ }^{\circ} \mathrm{C}$ & 90 & 82 & 87 \\
\hline Продолжительность, мин & 135 & 115 & 63 \\
\hline
\end{tabular}

Примечания. Концентрация массы на всех ступенях отбелки 10\%; условия обработки на ступенях Щ и ЩП традиционные: температура 60 и $70{ }^{\circ} \mathrm{C}$ соответственно, продолжительность 60 и 120 мин соответственно, расходы $\mathrm{NaOH}$ - по $1,5 \%$, а $\mathrm{H}_{2} \mathrm{O}_{2}-0,2 \%$ от абсолютно сухого волокна.

Таблица 2. Изменение основных характеристик сульфатной хвойной целлюлозы в процессе отбелки

\begin{tabular}{|c|c|c|c|c|c|}
\hline \multirow{3}{*}{ Показатели целлюлозы } & \multicolumn{5}{|c|}{ Величины показателей целлюлозы } \\
\hline & \multirow[b]{2}{*}{ исходной } & \multicolumn{4}{|c|}{ после отбелки по схемам } \\
\hline & & Пк - Щ & Пк - Щ - $\mathrm{X}_{1}$ & $\begin{array}{c}\text { Пк - Щ - } \mathrm{XT}_{1} \\
- \text { ЩП }\end{array}$ & $\begin{array}{r}\text { Пк }- \text { Щ }-\mathrm{X}_{\mathrm{T}_{1}}- \\
\text { Щ - } \mathrm{X}_{2}-\mathrm{K}\end{array}$ \\
\hline $\begin{array}{l}\text { Выход беленой целлюлозы, } \\
\text { \% от небеленой целлюлозы }\end{array}$ & - & 95,9 & 93,8 & 92,7 & 91,5 \\
\hline Число Каппа & 33,6 & 16,4 & 5,4 & 4,3 & - \\
\hline Медное число, г Cu/100г целлюлозы & 0,29 & 0,54 & 0,58 & 0,35 & 0,42 \\
\hline $\begin{array}{l}\text { Доля низкомолекулярной фракции } \\
\text { целлюлозы по Клейнеру (раствори- } \\
\text { мость в цинкате натрия), \% }\end{array}$ & 15,83 & 17,55 & 17,80 & 15,93 & 16,07 \\
\hline Белизна, \% & - & 41,5 & 66,3 & 78,0 & 88,0 \\
\hline Реверсия белизны, Рс & - & 2,75 & 2,04 & 1,45 & 0,75 \\
\hline Длина волокон (среднечисленная), мм & 1,575 & 1,563 & 1,642 & 1,598 & 1,615 \\
\hline
\end{tabular}

Из данных таблицы 2 следует, что пероксидная делигнификация целлюлозы позволяет снизить число Каппа более чем в 2 раза при весьма невысоких потерях волокна ( 4\%), более половины которых приходится на лигнин. Общие потери волокна при отбелке по полной схеме составили 8,5\%, в том числе примерно 4,7\% лигнина. Это свидетельствует о весьма избирательной делигнификации целлюлозы в процессе как кислой катализируемой пероксидной обработки, так и отбелки хлоритом натрия.

В предлагаемой схеме отбелки целлюлозы реализован принцип чередования кислых и щелочных ступеней, повышающий ее эффективность [1].

Изменения показателей, характеризующих степень окислительной деструкции целлюлозы (медное число, растворимость в цинкате натрия), происходят главным образом на ступени Пк (некоторое их повышение) и на ступени ЩП (соответственно, их понижение); однако величины этих изменений несущественны. Абсолютные величины этих показателей свидетельствуют о весьма умеренной степени окислительной деструкции целлюлозы в процессе отбелки.

На рисунке 1 представлено изменение в процессе отбелки показателей, характеризующих механическую прочность образцов целлюлозы. Из приведенных данных следует, что прочность целлюлозы умеренно снижается в процессе отбелки, что говорит о весьма мягких условиях отбелки целлюлозы на всех ступенях.

На рисунке 2 приведены микрофотографии волокон целлюлозы после каждой ступени обработки, на которых очень четко прослеживаются явления контракции волокон в кислой среде (на ступенях Пк, Хт, $\mathrm{X}_{2}$ ) и набухания - в щелочной (на ступенях Щ и ЩП).

Данные явления подтверждаются и изменением в процессе отбелки целлюлозы показателей, характеризующих геометрические параметры волокон (рис. 3).

Из рисунка 3 следует, что вследствие контракции ширина волокон на кислых ступенях $\mathrm{XT}_{1}$ и $_{\mathrm{XT}_{2}}$ меньше, чем на щелочных (Щ и ЩП). Длина волокон, наоборот, больше на кислых ступенях и меньше - на щелочных (см. табл. 2). Соответствующим образом, т.е. обратно пропорционально изменению длины волокон, изменяется и показатель «грубость волокон», характеризующий массу волокна, приходящуюся на единицу длины волокна. В целом же этот показатель снижается по ходу отбелки, что, вероятно, будет способствовать повышению эффективности размола целлюлозы. Фактор формы волокон, который характеризует степень прямолинейности волокна, в процессе отбелки снижается, но незначительно. Изменение его находится в прямой зависимости с изменением механической прочности целлюлозы. 


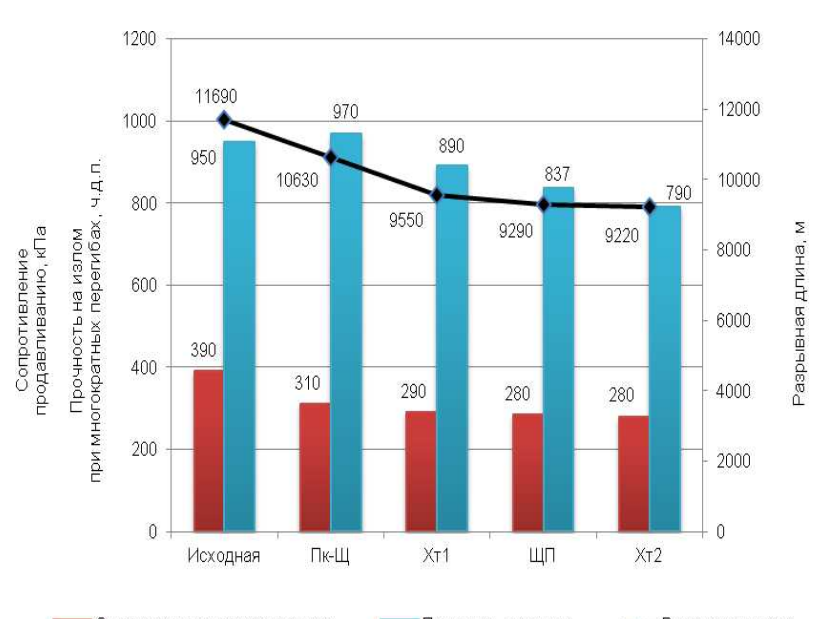

a)

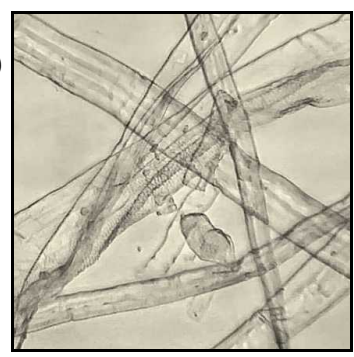

г)

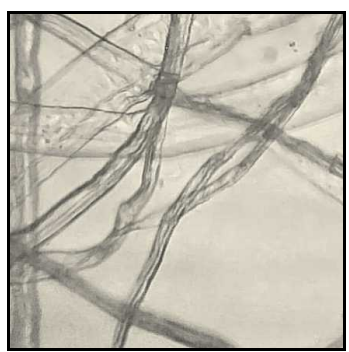

б)

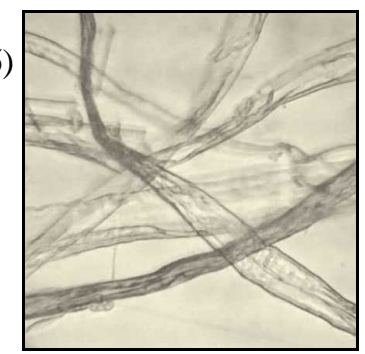

д)

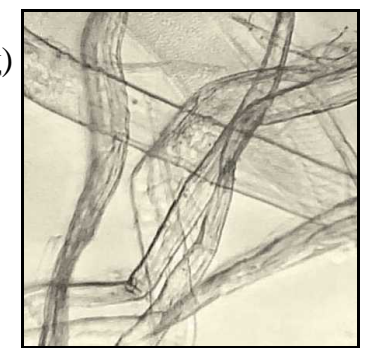

B)

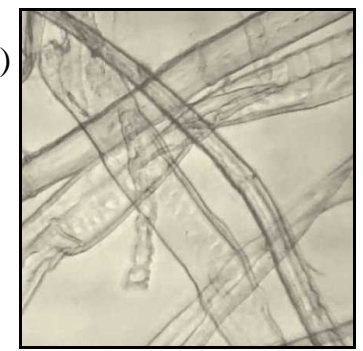

e)

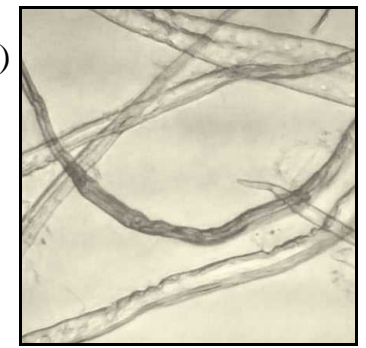

Рис. 2. Микрофотографии волокон сульфатной хвойной целлюлозы: $a$ - исходной; $\sigma$ - после Пк; $в$ - после

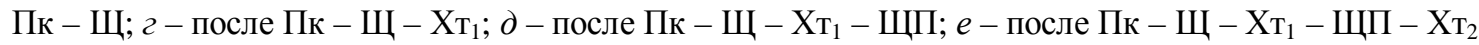

Для беленой целлюлозы, предназначенной для изготовления бумаги, очень важен показатель «водоудерживающая способность», которая характеризует поведение волокон целлюлозы на сеточной части бумагоделательной машины и отражается на процессах дальнейшего обезвоживания и сушки. Динамика изменения этого показателя в процессе отбелки отражена на рисунке 4.

Из рисунка 4 видно, что водоудерживающая способность целлюлозы, косвенно характеризующая величину удельной поверхности волокон (приходящейся на одно волокно), возрастает на первой ступени отбелки, что, по-видимому, происходит вследствие удаления лигнина. На последующих ступенях отбелки величины ее изменяются в соответствии с изменением $\mathrm{pH}$ - несколько снижаются в кислой среде за счет контракции волокон и возрастают на щелочной ступени вследствие их набухания. Аналогично изменяется и удельная поверхность волокон.

Фракционный состав целлюлозы по длине волокна в процессе отбелки изменяется незначительно в соответствии с делигнификацией целлюлозы.

Все вышеизложенное свидетельствует о весьма избирательном и мягком делигнифицирующем и отбеливающем воздействии на целлюлозу принятой схемы отбелки. 


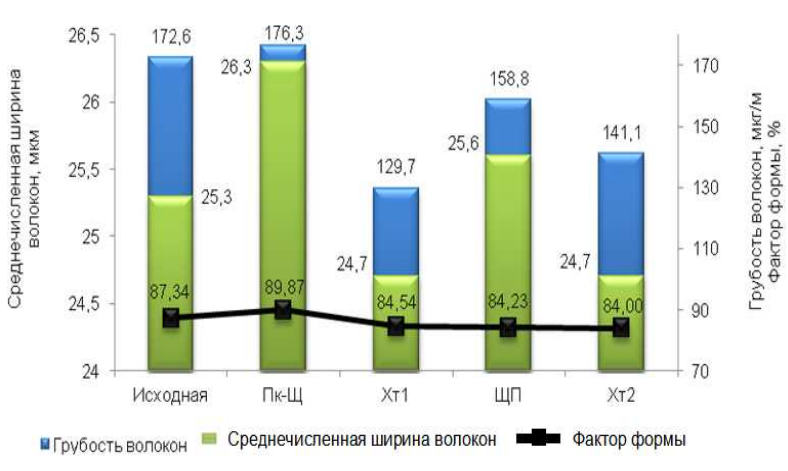

Рис. 3. Динамика изменений ширины волокон, грубости и фактора формы сульфатной хвойной целлюлозы в процессе отбелки

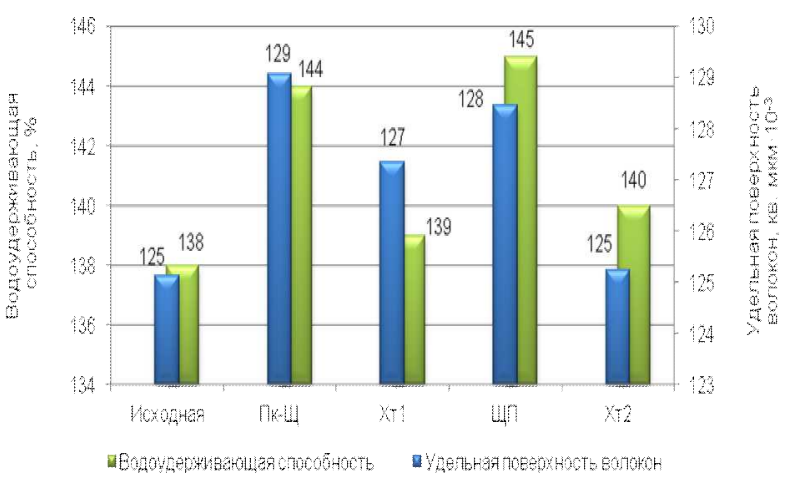

Рис. 4. Изменение водоудерживающей способности и удельной поверхности волокон сульфатной хвойной целлюлозы в процессе отбелки

\section{Заключение}

Результаты исследований показали, что при отбелке сульфатной хвойной целлюлозы даже с весьма высоким содержанием остаточного лигнина возможно и целесообразно использование пероксидно-щелочной делигнификации и отбелки хлоритом натрия (вместо $\mathrm{ClO}_{2}$ ). Отбелка целлюлозы с числом Каппа 33,6 по ЕСFсхеме Пк - Щ - Х $\mathrm{T}_{1}-$ ЩП - Х $\mathrm{T}_{2}-\mathrm{K}$ при разработанных оптимальных условиях позволяет получить целлюлозу белизной 88,0\% при сохранении показателей механической прочности. Это связано с весьма избирательной делигнификацией и умеренной окислительной деструкцией целлюлозы при отбелке по предлагаемой технологии. Более высокие результаты дает отбелка целлюлозы с несколько пониженным числом Каппа, используемым традиционно при отбелке на практике. Данная схема упрощает технологию отбелки, так как пероксидная обработка проводится при атмосферном давлении (в отличие от КЩО), а хлорит натрия - легко растворимый в воде химикат и не требует сложной подготовки перед использованием.

\section{Список литературы}

1. Аким Г.Л. Бесхлорная отбелка целлюлозы // Целлюлоза. Бумага. Картон. 2001. №5-6. С. 24-28.

2. Демин В.А. Активация и окисление лигнина в процессах отбелки сульфатной целлюлозы. 1. Механизм активации и окисления пероксидом водорода // Химия древесины. 1994. №3. С. 29-37.

3. Парен А., Яакара Й. Использование пероксомолибдата при ЕСF отбелке сульфатной целлюлозы // Целлюлоза. Бумага. Картон. 1999. №1-2. С. 20-23.

4. Пен Р.3. Планирование эксперимента в Statgraphics. Красноярск, 2003. 246 с.

5. Хакимова Ф.Х., Синяев К.А., Ковтун Т.Н. Отбелка сульфатной хвойной целлюлозы по ЕСF-технологии пероксидом водорода и хлоритом натрия // Лесной журнал. 2012. №4. С. 112-121.

6. Rabelo M.S., Colodette J.L., Sacon V.M., Silva M.R., Azevedo M.A.B. Molybdenum catalyzed acid peroxide bleaching of eucalyptus kraft pulp // BioResources. 2008. Vol. 3, N3. Pp. 881-897.

7. Taube F., Shchukarev A., Li J., Gellerstedt G., Agnemo R. Peroxomolybdate catalysts in pulp hydrogen peroxide bleaching: Improvement in hexeneuronic acid removal and delignification // Tappi Journal. 2008. N3. Pp. 8-14. 

PULP

Khakimova F.", Sinyaev K. HYDROGEN PEROXIDE AND SODIUM CHLORITE BLEACHING OF SULPHATE

Perm national research polytechnical university, Komsomolsky prospectus, 29, Perm, 614990 (Russia),

e-mail: tcbp@pstu.ru

The scheme $\mathrm{Pa}-\mathrm{E}-\mathrm{Ch}_{1}-\mathrm{EP}-\mathrm{Ch}_{2}$ is including delignification of pulp with hydrogen peroxide under acidic conditions in the presence of a molybdenum catalyst (Pa stage) and sodium chlorite bleaching under acidic conditions $\left(\mathrm{Ch}_{1}\right.$ and $\mathrm{Ch}_{2}$ stages). This scheme simplifies bleach technology of sulphate pulp because stages $\mathrm{O}$ and $\mathrm{D}$ are excluded. Degrees of oxidising and hydrolitic degradation of cellulose, regularity of change physical and chemical, structural and morphological properties of the pulp produced during $\mathrm{Pa}-\mathrm{E}-\mathrm{Ch}_{1}-\mathrm{EP}-\mathrm{Ch}_{2}$ scheme was determined. Bleaching of sulphate pulp with Kappa number 33,6 under the developed optimum conditions allows to receive pulp with a whiteness $88,0 \%$ and high level of mechanical strength.

Keywords: sulphate pulp, bleaching, hydrogen peroxide, sodium chlorite, properties of pulp and fibres.

\section{References}

1. Akim G.L. Tselliuloza. Bumaga. Karton, 2001, no. 5-6, pp. 24-28. (in Russ.).

2. Demin V.A. Khimiia drevesiny, 1994, no. 3, pp. 29-37. (in Russ.).

3. Paren A., Iaakara I. Tselliuloza. Bumaga. Karton, 1999, no. 1-2, pp. 20-23. (in Russ.).

4. Pen R.Z. Planirovanie eksperimenta v Statgraphics. [Design of experiments in Statgraphics]. Krasnoyarsk, 2003, 246 p. (in Russ.).

5. Khakimova F.Kh., Siniaev K.A., Kovtun T.N. Lesnoi zhurnal, 2012, no. 4, pp. 112-121. (in Russ.).

6. Rabelo M.S., Colodette J.L., Sacon V.M., Silva M.R., Azevedo M.A.B. BioResources, 2008, vol. 3, no. 3, pp. 881-897.

7. Taube F., Shchukarev A., Li J., Gellerstedt G., Agnemo R. Tappi Journal, 2008, no. 3, pp. 8-14.

Received September 20, 2012

\footnotetext{
* Corresponding author.
} 